\title{
Fetal Face as Predictor of Fetal Brain
}

\author{
Toshiyuki Hata
}

\begin{abstract}
We present recent topics regarding four-dimensional (4D) ultrasound assessment of fetal facial expressions to predict the development of the fetal brain. In several recent studies, the frequencies of seven facial expressions (mouthing, sucking, yawning, blinking, tongue expulsion, scowling/grimace, and smiling) were evaluated using 4D ultrasound. Fetal mouthing, sucking, yawning, blinking, tongue expulsion, scowling/grimace, and smiling may relate to feeding, feeding and purposeful behavior, sleep and arousal, wakefulness, feeding and speech functions, awareness, and emotion after birth respectively. Studies of the fetal face using 4D ultrasound will help elucidate the functioning of the fetal brain and the central nervous system (CNS), and help shed light on unknown areas of human biology.
\end{abstract}

Keywords: Facial expression, Fetal behavior, Fetal brain, Fetal face, Fetal movement, Four-dimensional ultrasound.

How to cite this article: Hata T. Fetal Face as Predictor of Fetal Brain. Donald School J Ultrasound Obstet Gynecol 2018;12(1):56-59.

Source of support: Nil

Conflict of interest: None

\section{INTRODUCTION}

In utero, no modality exists that can directly assess the fetal brain and CNS. However, it is considered that the movement and behavior of fetuses are related to them. ${ }^{1}$ The observation of fetal behavior is significant because, through it, the developmental and maturing functions of the fetal brain and CNS can be directly assessed. Therefore, fetal movements and behaviors have been reported to indicate the development of the fetal brain and $\mathrm{CNS}^{2,3}$ Recent advances leading to the development of $4 \mathrm{D}$ ultrasound have facilitated the straightforward detection of fetal movements, behaviors, and facial expressions. With 4D ultrasound, fetal movements and behavioral patterns during pregnancy can now be visualized. ${ }^{4-6}$ In this review article, we present recent topics on $4 \mathrm{D}$ ultrasound assessment of fetal facial expressions to predict the development of the fetal brain.

\section{Professor and Chairman}

Department of Perinatology and Gynecology, Kagawa University Graduate School of Medicine, Kagawa, Japan

Corresponding Author: Toshiyuki Hata, Professor and Chairman, Department of Perinatology and Gynecology, Kagawa University Graduate School of Medicine, Kagawa, Japan, Phone: +81878912174, e-mail: toshi28@med.kagawa-u.ac.jp

\section{FETAL MOVEMENTS LATE IN THE FIRST TRIMESTER AND EARLY SECOND TRIMESTER}

At 14 to 19 gestational weeks, Sajapala et al $^{7}$ used 4D ultrasound to examine the frequency of eight fetal movements in normal singleton pregnancies. As per their findings, isolated arm movements were the most common fetal movements at 14 to 16 and 17 to 19 gestational weeks, with the sole significant difference being the frequency of mouthing movement between 14 to 16 and 17 to 19 gestational weeks. In conclusion, they stated that the difference in the frequency of mouthing movement at 14 to 16 and 17 to 19 gestational weeks could be due to increased fetal swallowing caused by the increasing amniotic fluid early on the second trimester.

With the application of 4D ultrasound, differences in the fetal behavior before 20 gestational weeks between singleton and twin fetuses were assessed by AboEllail et $a .^{8}$ They found that arm and general movements were the most common in singletons, but only general movement was significantly more frequent compared with other six movements in twins at 12 to 13 gestational weeks. Significantly higher frequencies of arm and leg movements compared with those of the other six movements were noted at 14 to 19 gestational weeks in singletons, but only arm movement showed a significantly higher frequency than the other movements in twins. When fetal movements between singletons and twins were compared, the only significant difference was arm movement at 12 to 13 weeks, but the frequencies of all movements in singletons showed significantly higher values than twins at 14 to 19 gestational weeks. It was suggested that the limitation of space due to crowding of twin fetuses with gestational advancement markedly affects twin fetal movements on comparison with singletons, with this also true during the first half of pregnancy.

\section{FETAL FACIAL EXPRESSIONS}

Recent review articles on 4D ultrasound assessment of fetal facial expressions revealed the possibility that those expressions might be an important predictor of fetal brain function and development. ${ }^{4-6,9-12}$ In many recent studies, the frequencies of seven facial expressions (mouthing, sucking, yawning, blinking, tongue expulsion, scowling/ grimace, and smiling) during 15-minute recordings were assessed (Figs 1 to 7). Fetal mouthing, sucking, yawning, 

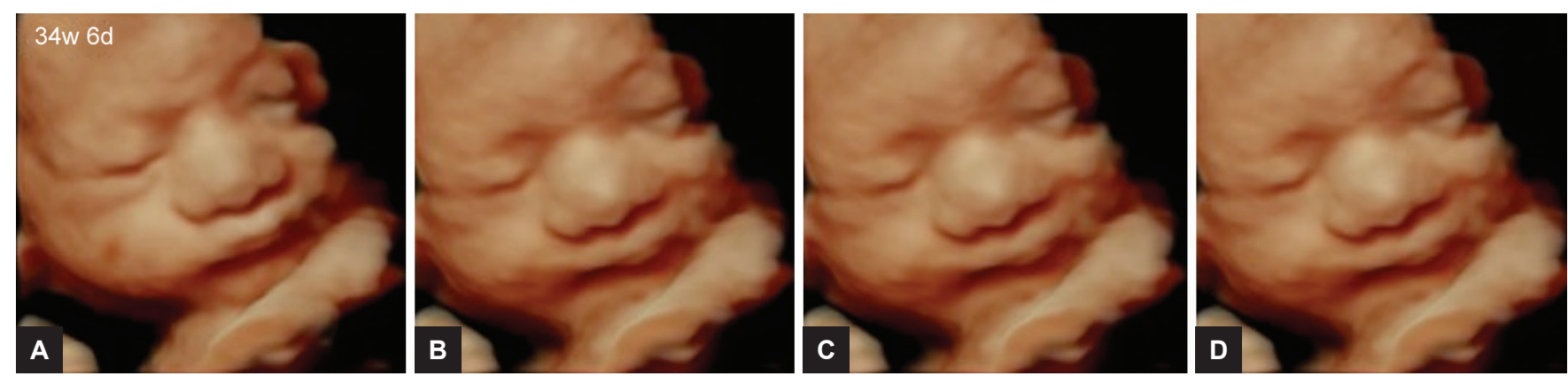

Figs 1A to D: Consecutive 4D ultrasound observation of fetal mouthing movements $(a \rightarrow d)$ at 34 weeks and 6 days of gestation
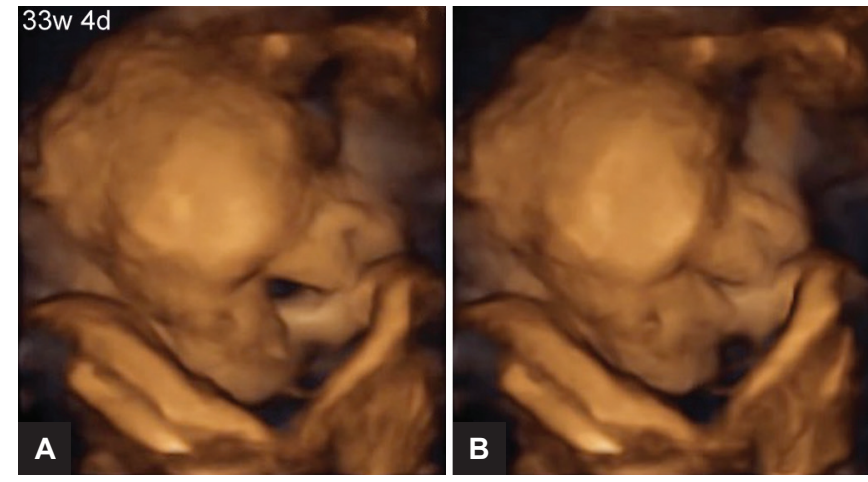

Figs 2A and B: Consecutive 4D ultrasound observation of fetal sucking movements $(a \rightarrow b)$ at 33 weeks and 4 days of gestation

blinking, tongue expulsion, scowling/grimace, and smiling may lead to feeding, feeding and purposeful behavior, sleep and arousal, wakefulness, feeding and speech functions, awareness, and emotion after birth respectively. In the latest study, mouthing was the most frequent facial expression at 36 to 40 weeks, followed by blinking. ${ }^{13}$ Both facial expressions are significantly more frequent than other expressions. This facial expression pattern is different from that before around 9 months of gestation. ${ }^{14-16}$

A diverse range of expressions, emotion-like movements, and reactions to various stimuli are shown by the

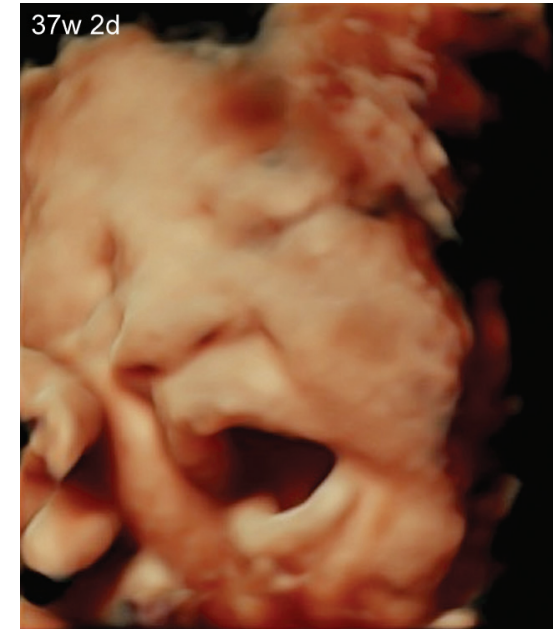

Fig. 3: Fetal yawning at 37 weeks and 2 days of gestation

fetal face. These represent the maturity and development of the brain and CNS. Such specific responses to stimuli also indicate high-level brain development and function. In utero, the facial movements and expressions captured may parallel the fetal brain function and development at various fetal stages. As such, the fetal face may be key to fully clarifying brain development and function, helping to elucidate the functional development of the human brain from the fetal period. ${ }^{11}$

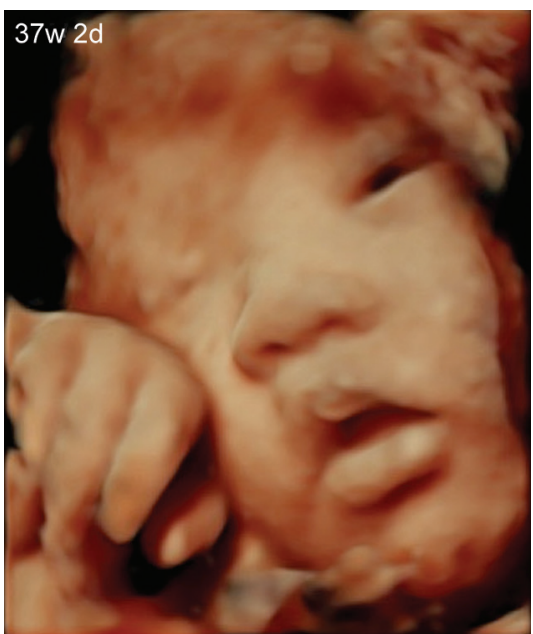

Fig. 4: Fetal eye opening at 37 weeks and 2 days of gestation

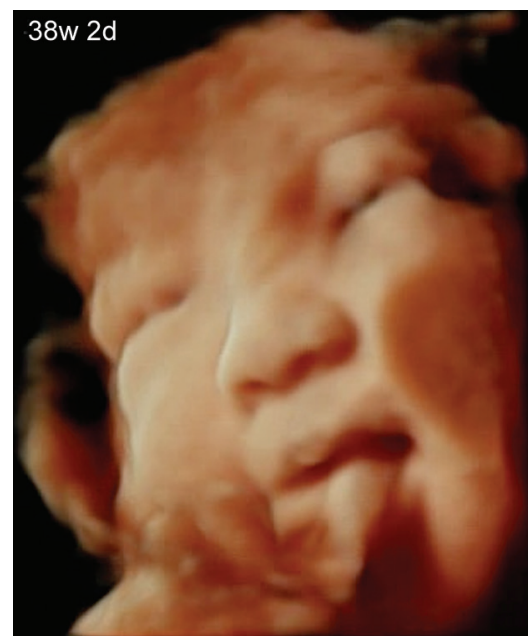

Fig. 5: Fetal tongue expulsion at 38 weeks and 2 days of gestation 


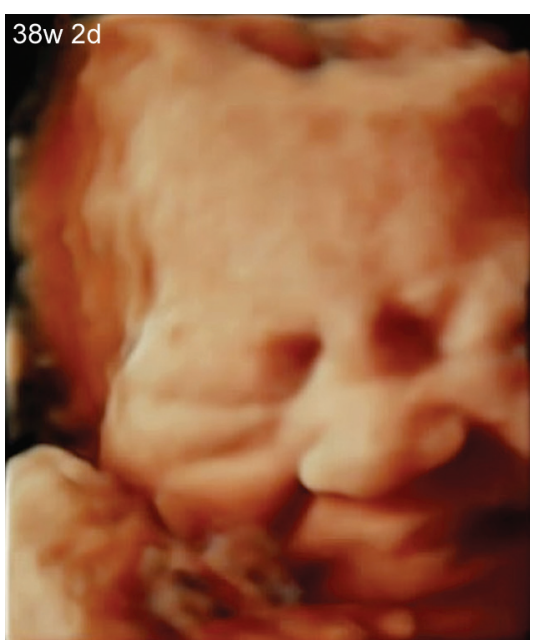

Fig. 6: Fetal scowling/grimace at 38 weeks and 2 days of gestation

\section{KURJAK'S ANTENATAL NEURODEVELOPMENTAL TEST}

With the use of Kurjak's Antenatal neurodevelopmental test (KANET), Hata et $\mathrm{al}^{17}$ assessed the sex-related differences in fetal behavior. They found that the total KANET score was normal in both males and females with the total KANET score showing no significant differences. On comparing single KANET parameters, there were no significant differences in all eight of the parameters examined. As a result, fetal neurobehavioral functions and developmental and maturational processes of the brain and CNS were concluded to be the same between males and females. Thus, any 4D ultrasound study on fetal behavior may not have to consider fetal sex.

Through examining the Asian and Caucasian populations, Hanaoka et $\mathrm{al}^{18}$ assessed the ethnic differences in fetal behavior. The total KANET score was normal in both populations, but a significant difference was noted in the total KANET scores on comparing Japanese and Croatian fetuses. On comparing single KANET parameters, four fetal movements showed no significant differences. However, two facial expression parameters showed a significant difference between the two populations. Based on this, ethnicity should be taken into consideration when assessing the fetal behavior, particularly on investigating the facial expressions of fetuses.

Antsaklis et $\mathrm{al}^{19}$ assessed whether there is a difference in the behavior of fetuses of diabetic pregnant women, compared with fetuses of nondiabetic pregnant women. In their results, the total KANET score in nondiabetic pregnant women was significantly higher than that in diabetic pregnant women. Looking at each KANET parameter, there were significant differences in three parameters: Isolated eye blinking, facial alterations, and finger movements. These authors stated that there are differences in the fetal behavior between diabetic

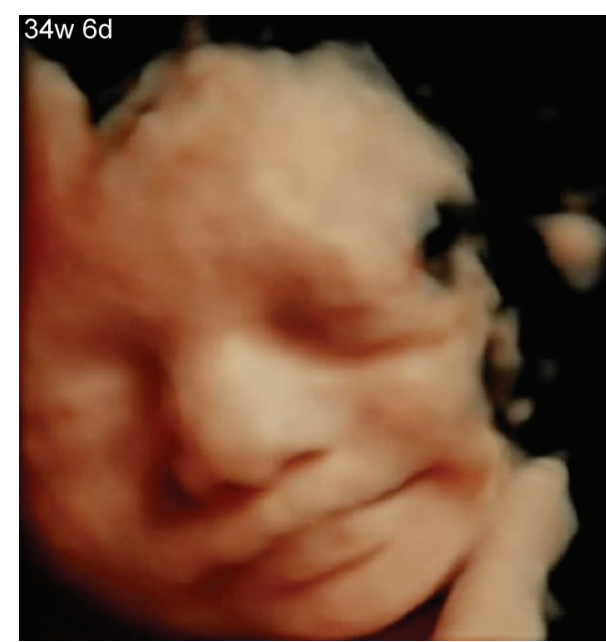

Fig. 7: Fetal smiling at 34 weeks and 6 days of gestation

and nondiabetic fetuses, and the specific parameters expressed by facial expressions were particularly different between the two groups.

\section{RECENT STUDIES ON FETAL BEHAVIORAL ASSESSMENT USING 4D ULTRASOUND}

At 14 to 39 gestational weeks, Lopez-Teijon et $\mathrm{al}^{20}$ used 4D ultrasound to examine the fetal facial expression in response to music applied intravaginally or abdominally. At $>16$ gestational weeks, the intravaginal music led to mouthing and tongue expulsion in $86.7 \%(\mathrm{p}=0.002)$ and $46.6 \%(\mathrm{p}=0.004)$ of all fetuses respectively, showing significant differences on comparison with abdominally applied music. As an explanation, the authors considered that neural pathways in the auditory-motor system are developed as early as week 16. It is possible that such findings will contribute to methods to diagnose prenatal hearing screening as well as research on fetal neurological stimulation.

There is an interesting study regarding the effect of maternal smoking on fetal mouthing movement assessed by $4 \mathrm{D}$ ultrasound at 24 to 36 weeks by Reissland et al. ${ }^{21}$ Therein, fetuses of mothers who had a smoking habit showed a significantly higher rate of mouth-movements compared with fetuses of nonsmokers $(p=0.02)$. These differences increased between the smoking and nonsmoking groups with the progression of pregnancy. The authors concluded that smoking mothers have fetuses that show more immature behavioral patterns compared with those of nonsmokers.

In a study of the reaction to the maternal voice, Marx and $\mathrm{Nagy}^{22}$ assessed the fetal behavioral responses with $4 \mathrm{D}$ ultrasound at 21 to 33 gestational weeks. Fetuses showed more movements of the arm, head, and mouth when the mother touched her abdomen and showed reduced arm and head movements in response to the maternal voice. In the third trimester, fetuses exhibited 
increased regulatory (yawning), resting (arms crossed), and self-touch (hands touch the body) responses on comparison with second trimester fetuses. It was found that fetuses showed an earlier selective response to external stimuli than reported. In response to external stimulation, the fetal behavior was actively regulated. These differential responses to the environment were influenced by fetal maturation.

It was reported that third trimester human fetuses prefer viewing face-like stimuli in comparison with the same stimuli adopting an inverted configuration, by Reid et al. ${ }^{23}$ They considered that this predisposition does not necessitate postnatal experience, and it was clarified that it is possible to deliver visual stimuli via maternal tissue to the fetus.

\section{CONCLUSION}

Diverse facial expressions are shown by the fetus, including emotion-like movements and reactions responding to diverse stimuli. Such expressions and reactions exemplify the maturity and development of different regions of the brain and CNS. Furthermore, a high degree of brain development and function is indicated by selective responses to stimuli. Therefore, in utero, movements and expressions discerned by $4 \mathrm{D}$ ultrasound can directly represent the fetal brain function and development in different fetal stages. As such, the fetal face may be key fully clarifying fetal brain development and function, helping to elucidate the functional development of the human brain from the early fetal period. ${ }^{11}$ The advent of $4 \mathrm{D}$ ultrasound has led to the development of novel academic disciplines, such as "fetal neurology" and "fetal psychology," and heralded the dawn of a new phase in fetal behavioral science. It is my hope that this modality will markedly advance research on the fetal brain and CNS. ${ }^{10}$ Studies on fetal behavior will help elucidate the secret functioning of the fetal brain and CNS, and help shed light on unknown areas of human biology.

\section{REFERENCES}

1. Hepper PG. Fetal behavior: why so skeptical? Ultrasound Obstet Gynecol 1996;8:145-148.

2. Prechtl HF. State of the art of a new functional assessment of the young nervous system: an early predictor of cerebral palsy. Early Hum Dev 1997 Nov;50(1):1-11.

3. Nijhuis JG. Fetal behavior. Neurobiol Aging 2003 MayJun;24(Suppl 1):S41-S46; discussion S47-S49, S51-S52.

4. Hata T, Dai SY, Marumo G. Ultrasound for evaluation of fetal neurobehaviour development: from 2-D to 4-D ultrasound. Inf Child Dev 2010 Jan-Feb;19(1):99-118.

5. Hata T, Kanenishi K, Hanaoka U, Uematsu R, Marumo G, Tanaka H. HDlive study of fetal development and behavior. Donald School J Ultrasound Obstet Gynecol 2014 Jul-Sep; 8(3):250-265.
6. Hata T, Kanenishi K, Akiyama M, Tanaka H, Kimura K. Realtime 3-D sonographic observation of fetal facial expression. J Obstet Gynaecol Res 2005 Aug;31(4):337-340.

7. Sajapala S, AboEllail MA, Kanenishi K, Mori N, Marumo G, Hata T. 4D ultrasound study of fetal movement early in the second trimester of pregnancy. J Perinat Med 2017 Aug;45(6):737-743.

8. AboEllail MA, Kanenishi K, Mori N, Noguchi J, Marumo G, Hata T. Ultrasound study of fetal movements in singleton and twin pregnancies at 12-19 weeks. J Perinat Med 2017 Sep.

9. Hata T, Kanenishi K, Hanaoka U, Marumo G. HDlive and 4D ultrasound in the assessment of fetal facial expressions. Donald School J Ultrasound Obstet Gynecol 2015 Jan-Mar;9(1):44-50.

10. Hata T, Kanenishi K, AboEllail MA, Marumo G, Kurjak A. Fetal consciousness 4D ultrasound study. Donald School J Ultrasound Obstet Gynecol 2015 Oct-Dec;9(4):471-474.

11. AboEllail MA, Hata T. Fetal face as important indicator of fetal brain function. J Perinat Med 2017 Aug;45(6):729-736.

12. AboEllail MA, Hata T. Fetal face and 4D. In: Kurjak A, Chervenak FA, editors. Donald school textbook of ultrasound in obstetrics and gynecology. New Delhi: Jaypee Brothers Medical Publishers (P) Ltd.; 2016.

13. AboEllail MA, Kanenishi K, Mori N, Mohamed OA, Hata T. $4 \mathrm{D}$ ultrasound study of fetal facial expressions in the third trimester of pregnancy. J Matern Fetal Neonatal Med 2018 Jul;31(14):1856-1864..

14. Yan F, Dai SY, Akther N, Kuno A, Yanagihara T, Hata T. Fourdimensional sonographic assessment of fetal facial expression early in the third trimester. Int J Gynecol Obstet 2006 Aug;94(2):108-113.

15. Kanenishi K, Hanaoka U, Noguchi J, Marumo G, Hata T. 4D ultrasound evaluation of fetal facial expressions during the latter stages of the second trimester. Int J Gynecol Obstet 2013 Jun;121(3):257-260.

16. Sato M, Kanenishi K, Hanaoka U, Noguchi J, Marumo G, Hata T. 4D ultrasound study of fetal facial expressions at 20-24 weeks of gestation. Int J Gynaecol Obstet 2014 Sep;126(3):275-279.

17. Hata T, Hanaoka U, AboEllail MA, Uematsu R, Noguchi J, Kusaka T, Kurjak A. Is there a sex difference in fetal behavior? A comparison of KANET test between male and female fetuses. J Perinat Med 2016 Jul;44(5):585-588.

18. Hanaoka U, Hata T, Kanenishi K, AboEllail MA, Uematsu R, Konishi Y, Kusaka T, Noguchi J, Marumo G, Vasilj O, et al. Does ethnicity have an effect on fetal behavior? A comparison of Asian and Caucasian populations. J Perinat Med 2016 Mar;44(2):217-221.

19. Antsaklis P, Porovic S, Daskalakis G, Kurjak A. 4 D assessment of fetal brain function in diabetic patients. J Perinat Med 2017 Aug;45(6):711-715.

20. Lopez-Teijon M, Garcia-Faura A, Prats-Galino A. Fetal facial expression in response to intravaginal music emission. Ultrasound 2015 Sep;23(4):216-223.

21. Reissland N, Francis B, Kumarendran K, Mason J. Ultrasound observations of subtle movements: a pilot study comparing foetuses of smoking and nonsmoking mothers. Acta Paediatr 2015 Jun;104(6):596-603.

22. Marx V, Nagy E. Fetal behavioural responses to maternal voice and touch. PLoS One 2015 Jun;10(6):e0129118.

23. Reid VM, Dunn K, Young RJ, Amu J, Donovan T, Reissland N. The human fetus preferentially engages with face-like visual stimuli. Curr Biol 2017 Jul;27(13):1825-1828. 